Fanum

Sociológico

\section{Forum Sociológico}

Série II

17 | 2007

Envelhecimento activo. Um novo paradigma

\title{
Reflectindo sobre o conceito de envelhecimento activo, pensando no envelhecimento em meio urbano
}

Paulo Machado

\section{(2) OpenEdition \\ Journals}

Edição electrónica

URL: https://journals.openedition.org/sociologico/1646

DOI: $10.4000 /$ sociologico.1646

ISSN: 2182-7427

Editora

CICS.NOVA - Centro Interdisciplinar de Ciências Sociais da Universidade Nova de Lisboa

\section{Edição impressa}

Data de publição: 1 janeiro 2007

Paginação: 53-63

ISSN: 0872-8380

Refêrencia eletrónica

Paulo Machado, «Reflectindo sobre o conceito de envelhecimento activo, pensando no envelhecimento em meio urbano», Forum Sociológico [Online], 17 | 2007, posto online no dia 01 janeiro 2007, consultado o 30 março 2022. URL: http://journals.openedition.org/sociologico/1646 ; DOI: https://doi.org/10.4000/sociologico.1646 


\title{
REFLECTINDO SOBRE O CONCEITO DE ENVELHECIMENTO ACTIVO, PENSANDO NO ENVELHECIMENTO EM MEIO URBANO
}

\author{
Paulo Machado \\ Investigador no LNEC, doutor em sociologia (pmachado60@gmail.com)
}

\begin{abstract}
Resumo
Nas sociedades Ocidentais as questões do envelhecimento activo ganharam o estatuto de agenda política e orientam, hoje, os esforços para promover o bem-estar social da geração idosa. O texto apresenta o conceito de envelhecim ento activo, propõe o seu equacionam ento sociológico e defende a integração das medidas de política social no quadro das políticas do território.
\end{abstract}

Palavras-chave: Envelhecimento activo, política social, envelhecimento demográfico.

\begin{abstract}
In the Western societies active ageing is on the political agenda and presently guide the efforts to promote the social well-being of the elderly. This paper presents the concept of active ageing, questions it from a sociological perspective and argues for the integration of social policies measures in the territory policy framework.
\end{abstract}

Keyw ords: Active ageing, social policy, demographic ageing.

\section{Justifica-se uma sociologia do envelhecimento activo?}

A aparente inocuidade do conceito de enveIhecimento activo na abordagem sociológica do envelhecimento demográfico e da velhice é algo para que os sociólogos devem estar desconfiados, não tanto pelo que revela, mas sobretudo pelo que escam oteia. Vale aqui o conselho de Alain Touraine a propósito da reacção que aprendemos a ter contra todas as categorias de interpretação que fazem parte do conjunto das categorias da prática social. Para Touraine, a problematização do óbvio e a desconstrução da (falsa) realidade tem que fazer "arrancar os factos sociológicos dos factos sociais em que aqueles estão encerrados" (Touraine, 1982: 25). Em verdade, trata-se de um requisito do método de investigação sociológica: pode não ser novo, mas é bastante oportuno.

Se nos detivermos sobre o conceito de enveIhecimento activo apercebemo-nos da sua intencionalidade: "o envelhecimento activo é o processo de optimização de oportunidades de saúde, participação e segurança visando o aumento da qualidade vida das pessoas à medida que envelhecem" (WHO, 2002).
Inscrevendo-se numa lógica de produção social cuja correcção política e bondade humana são aceites (é politicam ente correcto e socialmente partilhado defender-se um envelhecimento amigável do cidadão mais velho), este conceito carece, porém, de um equacionam ento sociológico próprio. A questão sociológica consiste em perceber porque se fala e entende por envelhecimento activo. Compreender, depois, o modo de criação e distribuição das oportunidades de saúde, participação e segurança, ou seja, a sua natureza socialmente assimétrica, o seu alcance real e as formas pelas quais os sujeitos e os seus grupos sociais se apropriam dessas mesmas oportunidades; e, finalmente, perceber os contextos sociais e ambientais em que tais oportunidades se concretizam. Trata-se de uma agenda que o presente texto não pretende cumprir integralmente, mas para a qual gostaríamos de contribuir.

A Organização Mundial de Saúde (WHO, 2002: 20-32), na apresentação da sua agenda política para a promoção do envelhecimento activo não deixa de reflectir, parcialmente, estas mesmas preocupações, nomeadamente quando identifica um conjunto de influências, que denomina "determinantes", susceptíveis de poderem desempenhar um papel relevante no 
envelhecimento activo, seja como factores positivos, seja como obstáculos - neste último caso, funcionando como bloqueadores da mudança social que as políticas de envelhecimento activo se propõem ser. De entre os muitos determinantes que se poderiam identificar, sublinhamos os seguintes:

- Cultura ("culture, which surrounds all individuals and populations, shapes the way in which we age because it influences all of the other determinants of active ageing");

- Género ("gender is a «lens» through which to consider the appropriateness of various policy options and how they will affect the well being of both men and women");

- Sistema de saúde e de apoio social ("to promote active ageing, health systems need to take a life course perspective that focuses on health promotion, disease prevention and equitable access to quality primary health care and long-term care");

- Comportamento saudável ("the adoption of healthy lifestyles and actively participating in one's own care are important at all stages of the life course. One of the myths of ageing is that it is too late to adopt such lifestyles in the later years. On the contrary, engaging in appropriate physical activity, healthy eating, not smoking and using alcohol and medications wisely in older age can prevent disease and functional decline, extend longevity and enhance one's quality of life");

- Factores pessoais e ambientais ("while genes may be involved in the causation of disease, for many diseases the cause is environmental and external to a greater degree than it is genetic and internal": 26. "The great majority of injuries are preventable; however, the traditional view of injuries as "accidents" has resulted in historical neglect of this area in public health");

- Ambiente social ("social support, opportunities for education and lifelong learning, peace, and protection from violence and abuse are key factors in the social environment that enhance health, participation and security as people age");

- Economia ("concentrating only on work in the formal labour market tends to ignore the valuable contribution that older people make in work in the informal sector (e.g., small scale, self-employed activities and domestic work) and unpaid work in the home").

$\mathrm{Na}$ tarefa de interpretação deste quadro de referência, salta para a mesa do investigador a sua forte ocidentalidade, pese embora a vocação universal que caracteriza o emissor. A associação a conceitos satélites que nos habituám os a reconhecer na agenda da política social contemporânea, tais como, autonomia, independência, participação, qualidade de vida, esperança de vida, esperança de vida sem incapacidades, solidariedade intergeracional, entre outros, é bastante evidente. Tal galáxia conceptual decorre do modo próprio como as sociedades Ocidentais construíram, sobretudo a partir da tomada de consciência do envelhecimento das suas estruturas demográficas, a noção de pessoa idosa, e como agiram em conformidade com essa noção.

Fora do perímetro alargado do Velho Mundo, onde a influência da socialização geronte Ocidental é menos acentuada, e onde a descapitalização social dos mais velhos é menos evidente - muito embora se saiba existirem problemas sociais sérios entre a população mais idosa, em estreito alinhamento com os problemas da população em geral - a noção de envelhecimento activo será, no mínimo, estranha como já o haviam sido, algumas décadas antes, as noções de $3^{\underline{a}}$ e $4^{\underline{a}}$ Idades. Nas sociedades Ocidentais, somente quando os quadros e os processos de acção social revelaram sinais de fragmentação geracional dir-se-ia, acompanhando Boaventura Sousa Santos (1998), turbulências no sistema comum de valores, gerando estranhamento, desfamilização, surpresa, perplexidade - é que a questão da geração idosa, como se de um corpo social estranho se tratasse, se veio a colocar. Essa (nova) situação demográfica gerou uma crise do paradigma social, político e cultural do contrato social moderno, na medida em que ele se tornou ao mesmo tempo proeminente mas insatisfatório (perante as necessidades). O empurrão dos mais velhos para fora da lógica de criação do Produto Nacional, e a sua subsidiação forçada, criou dependência, inactividade, e muitos desiguais ganhos em termos de qualidade de vida. Sobretudo, criou um vazio temporal muito alargado, porquanto tais mudanças no Ocidente são contem porâneas do aumento da esperança de vida depois dos 65 anos de idade.

Há, por conseguinte, que não confundir a importância das soluções do Estado de Bem- Estar com o paraíso na Terra. Para os idosos que foram toda a vida assalariados com baixas remunerações, ou para aqueles que tão-pouco exerceram actividades remuneradas - as prestações sociais, nomeadamente pecuniárias, equivalem objectivamente à diferença entre a sobrevivência e indigência extrema. De outro modo, estariam condenados a uma dependência directa dos seus familiares e da filantropia da comunidade próxima. A suspensão das prestações sociais numa sociedade envelhecida corresponderia a uma catástrofe social de amplitude inimaginável.

Porém, a oportunidade as soluções que procurem satisfazer as necessidades sociais de bem- estar de uma percentagem crescente da população 
é, igualmente, uma evidência, e é neste contexto que deveremos perceber o alcance, tanto quanto as limitações, da agenda do envelhecimento activo. É nesta perspectiva que encontramos um campo analítico propício ao desbravar de uma sociologia do envelhecimento activo, que perscrute a medida política e a distinga da realidade social para a qual se dirige, discutindo, em ultima ratio, a sua justificação.

\section{O alongamento e a dilatação geracionais}

Observe-se como a dilatação das coortes nos últimos anos de vida se vem manifestando na sociedade portuguesa (ver Gráfico 1). Nas últimas três décadas os ganhos de tempo de vida foram crescendo linearmente e revelam diferenças de 5,2 anos para as mulheres e de 4,2 anos para os homens. Os reflexos desta transform ação do ciclo de vida nas estruturas populacionais não poderiam deixar de se manifestar, entre outros indicadores, no índice de longevidade ${ }^{1}$ (em 2006 atingiu os $45 \%$, tendo aumentado quase 4 pontos percentuais desde 2000).

Esta alteração do calendário social ${ }^{2}$ acarretou que as coortes se extingam cada vez mais tarde, mas sobretudo que um cada vez maior número de homens idosos e (sobretudo) mulheres idosas estejam vivos durante mais tempo. O aumento da esperança de vida é um indicador de desenvolvimento económico e social, uma espécie de triunfo da ciência e das políticas públicas (sanitárias, sociais, de rendimento) sobre as causas da mortalidade precoce que ceifava um grande número de vidas num passado não muito distante do nosso presente.

Tal significa que o senso comum se engana quando lamenta a precocidade da morte na sociedade contemporânea, mas o aforismo é válido para sufragar a proposição de Riley (1988), segundo a qual o modo como as pessoas envelhecem é afectado pelas características da coorte a que pertencem e pelas mudanças ambientais, culturais e sociais às quais a sua coorte foi exposta, ao mover-se por sucessivos estratos etários. Porque a sociedade muda, os membros das sucessivas coortes envelhecem de maneira diferente. Não existirão, neste domínio, excepções entre as diferentes formações sociais.

No que respeita à concentração da morte nos últimos grupos etários, os últimos dados disponíveis (referentes a 2006) indicam que mais de $87 \%$ dos óbitos de mulheres ocorridos em Portugal e mais de $74 \%$ dos masculinos respeitaram a pessoas com, pelo menos, 65 anos. Dez anos antes, esses valores eram, respectivamente, de $85 \%$ e $70 \%$. A concentração da mortalidade nos últimos anos de vida das coortes é cada vez maior. Se recuarmos algumas décadas (ver Gráfico 2, limitado à representação até 2001) apercebemo-nos de que a morte envelheceu: perdeu saliência nas camadas etárias infantis, muito jovens, jovens e adultas e entrincheirou-se na geração idosa. A observação de longo prazo permite reter

Gráfico $1 \triangleright$ Evolução da Esperança de vida aos 65 anos, por Sexo, em Portugal

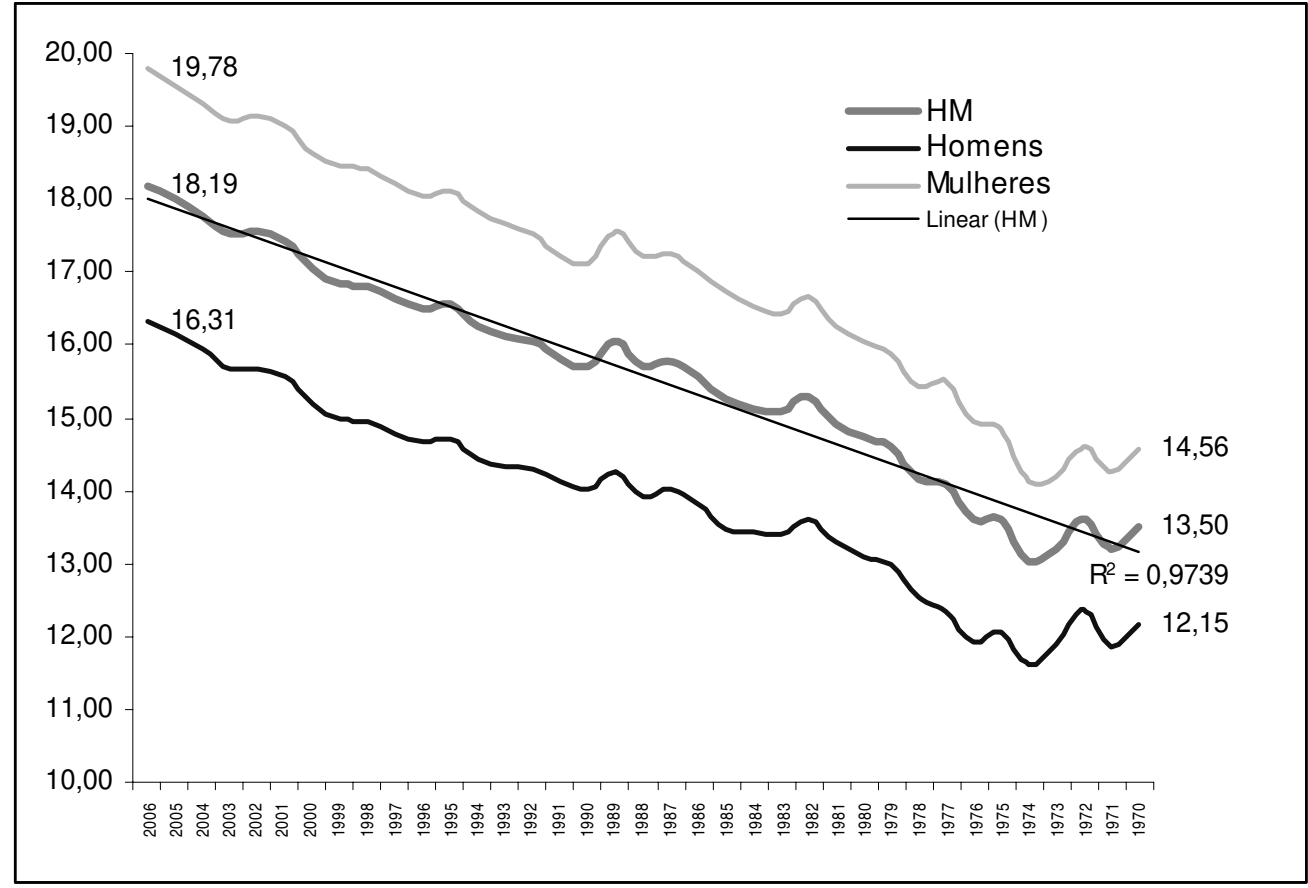

Fonte: INE, Indicadores Demográficos para o período de referência (1970 a 2006) 
que os óbitos das pessoas idosas representavam, no final da década de 30 , cerca de $1 /{ }_{3}(34 \%)$ do total de óbitos registados, contra os $4 / 5$ (81\%) em 2006. Concomitantemente, a proporção de óbitos das pessoas muito idosas (i.e., com mais 80 anos) no conjunto do obituário da geração idosa, que era minoritária em 1939 (36\%), chegou aos nossos dias como maioritária ( $58 \%$ em 2006$)$ - ou seja, a maioria dos idosos morre com mais de 80 anos. 0 reforço desta tendência acentuou-se, sobretudo, a partir da década de 80.

As mudanças dos padrões de mortalidade (e também da morbilidade) que se podem sinalizar como ocorridas nas últimas décadas, deixam perceber o porquê da existência de um maior número de pessoas mais velhas, mas obrigam a interrogar-nos sobre como se poderão manter activas. Haverá por aqui uma formulação idealística correspondente à vontade de retardar a morte? Algo congruente com uma representação social da morte enquanto acontecim ento desprovido de sentido, progressivamente desritualizada, empobrecida em termos de sentimentos e expressões ${ }^{3}$, e cada vez mais hospitalizada e medicalizada, de que resulta a sua invisibilidade social (Martins, 1985), em total contraste com a morte domesticada, da resignação ao inevitável de que nos falava Ariès (1977) para um período não muito recuado da nossa história.

\section{O processo de envelhecimento individual: parente pobre da abordagem sociológica}

Dir-se-ia que o envelhecimento de um ser humano é um processo cujo resultado é óbvio, mas cujo mecanismo permanece desconhecido. Por envelhecimento biológico pode entender-se a incapacidade progressiva - resultante do declínio do sistema imunitário do organismo - em se adaptar às condições variáveis do seu ambiente. A diminuição do volume dos tecidos - que pode igualmente ocorrer na sequência de um qualquer processo patológico independente do processo de envelhecimento - é, porventura, a manifestação física mais evidente, mas não suficiente para a catalogação de "velho". Concomitante a esta diminuição, aumenta a preponderância dos tecidos conjuntivos, em detrimento do parênquima, que se vê invadido pelos primeiros, acarretando a modificação da sua estrutura e função.

Esta modificação é designada por esclerose, conceito que se incorporou no vocabulário comum, e que tende para uma utilização sinónima de estado de velhice: "estar esclerosado" significa, na generalidade das situações em que a expressão é empregue, "estar velho". No entanto, no domínio das ciências da vida permanecem largas manchas de desconhecimento e campo aberto para diferentes desenhos teóricos. Parecendo prevalecer as teorias que atribuem a primazia às modificações, com

Gráfico $2 \triangleright$ Evolução de longo prazo na estrutura etária da mortalidade em Portugal - óbitos das gerações idosa (65+ anos) e muito idosa ( $85+$ anos)

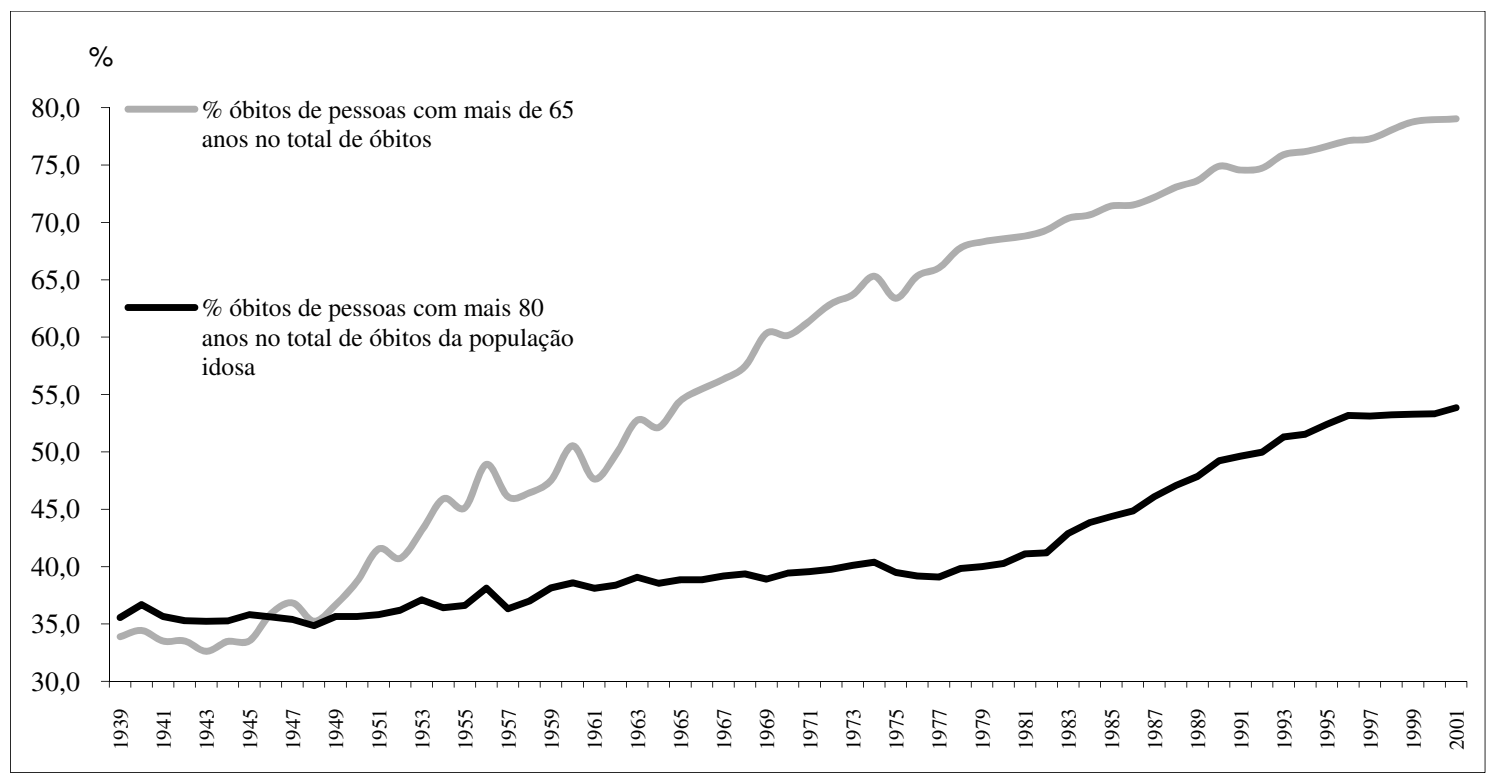

Fonte: dados retirados de INE - séries cronológicas: TEMA: C - População e Condições Sociais; SUBTEMA: 02 - Demografia e Censos. Cálculos efectuados por nós. 
a idade, de certos tecidos ou de certas células ${ }^{4}$, existe um consenso na bibliografia das especialidades geriátrica e gerontológica relativamente a três aspectos do envelhecimento que importa sublinhar numa discussão sobre o significado de envelhecimento activo:

$1^{\circ}$. O envelhecimento humano está associado ao declínio, mais ou menos rápido, das funções fisiológicas, histológicas, bioquímicas ou genéticas, ainda que esse declínio varie de função para função e em cada pessoa;

2 ․ Não existe uma causa única para o envelhecimento: este processo é, provavelmente, resultante de um complexo sistema de causas intrínsecas (ao sujeito) e extrínsecas (i.e., relativas ao meio ambiente a que pertence), sendo a noção de causa entendida, dada a incerteza do resultado, como o elemento que aumenta a probabilidade do acontecimento;

3 . O envelhecimento hum ano acarreta consequências no comportamento do indivíduo, enquanto actor social.

De acordo com o que vimos defendendo (Machado, 2007), suportados pela perspectiva ecológica em sociologia, e orientados para o estudo da mudança social, do envelhecimento demográfico e da velhice em meio urbano, qualquer um destes três aspectos ganha uma actualidade considerável, e reforça a consistência dos argumentos sócio-ecológicos. O declínio funcional repercutir-se-á nos processos transaccionais pessoa-ambiente, e terá implicações não despiciendas nos níveis de congruência ecológica que garantem a satisfação das necessidades de bem-estar dos idosos e a sua qualidade vida. Estas considerações são relevantes na abordagem, por exemplo, da sua mobilidade no meio ambiente urbano, na apreciação da sua acuidade cognitiva, designadamente sobre os riscos urbanos, e na sua avaliação (perceptiva) desses mesmos riscos.

Simultaneamente, e numa perspectiva sistémica, as alterações do ambiente urbano (as causas extrínsecas a que nos referimos) não deverão ser menosprezadas na compreensão do processo de envelhecimento individual, e porventura explicá-lo-ão parcial e indirectamente, pelo menos em termos dos padrões da sua morbilidade. Destacaríamos, neste âmbito, as questões ambientais que interferem, sobremaneira, no quotidiano das cidades, designadamente as que se referem à (falta) de qualidade do ar, ao ruído, à temperatura e às am eaças bacterianas. Acrescentaríamos, pela sua actualidade, a questão da sinistralidade do peão urbano idoso.

Assim, é lícito admitir que os parâm etros bioquímicos e hem atológicos que caracterizam as coortes envelhecidas na sociedade contemporânea podem não significar exclusivamente efeitos de idade, mas também de geração: em rigor, podem ser entendidos como parâm etros fisiológicos sociologicam ente explicáveis. A dieta alimentar, os consumos de álcool, o tabagismo, as condições de trabalho a que foram expostos durante um período longo da sua vida, a ausência de políticas de saúde preventivas (que se verificou durante décadas) e deficientes condições habitacionais - que frequentem ente ainda perduram - são elem entos considerados relevantes na caracterização do actual estado de saúde das gerações mais idosas. O individual inscreve-se, deste modo, no social e é parcialmente explicado por este. Trata-se de uma relação explicativa muito promissora que os estudos interdisciplinares podem ajudar a desenvolver.

No mesmo sentido, e no que respeita à saúde mental, os efeitos de geração e de idade têm sido evidenciados para explicar a elevada prevalência de perturbações mentais e comportamentais na velhice (OMS, 2002). A depressão, muito comum entre os idosos, é ainda mais expressiva entre os idosos com perturbações físicas incapacitantes. As perturbações mentais são, com alguma frequência, erradamente consideradas como fazendo parte do processo de envelhecimento, facto que não é, de todo, irrelevante em face do chamado efeito retroactivo das representações sociais sobre os modelos de interacção (mesmo dentro dos subsistemas sociais periciais) intergeracional e sobre as práticas sociais correspondentes. $\mathrm{O}$ fenóm eno de ancianismo (ageism) - identificado pelas atitudes negativas perante a velhice - inscreve-se neste quadro e pode ser convocado como tópico relevante para se compreender o envelhecimento humano e a associação que se pode estabelecer com a mudança social.

Esta abordagem não nos pode conduzir a um reducionismo sociológico abstractizante - que corresponderia a tudo explicar por via da sociogénese -, nem fazer esquecer a nossa base filogenética como algo que determina o limite de vida dos sistemas orgânicos, pese embora a elevada variabilidade interindividual. Mas não é errado falar de um envelhecimento socialmente diferenciado quando identificamos situações precedentes com uma causalidade relevante, respeitantes a determinados grupos sociais, e distintas de outras que respeitam a outros grupos sociais. Os estudos sobre os diferenciais de esperança de vida (INE, 2000) - muito desenvolvidos na década de 80 - ou os estudos epidemiológicos sobre a incidência de determinadas patologias com desigual incidência em coortes geracionais (INSA, 2001), resultam em larga medida do accionamento dos princípios da causalidade - pelo menos em termos de associação estatística - que se podem convocar para afirmar a influência (capacidade explicativa) de determinados factores precedentes sobre os fenómenos que procuramos explicar. 
Vejamos como a psicogerontologia, sob uma perspectiva ecológica (Paúl, 1991), equaciona a diversidade que ocorre no processo de envelhecimento:

\footnotetext{
"Não devemos deixar de colocar a hipótese de se verificar a nível intra-individual uma indiferenciação de sistemas em que as várias esferas da vida, biológica, psicológica, social, estão de novo de tal forma imbricadas, que a alteração em qualquer dos sistemas tem implicações directas e profundas em todos os outros. O comportamento dos idosos surge-nos muito como um todo, em que uma alteração no sistema biológico, um agravamento de uma deficiência sensorial ou motora, o desaparecimento de mais um ente querido da sua rede social de apoio, por exemplo, se confundem com uma disfunção do humor, apatia, ou a perda de capacidades cognitivas. Mas ao contrário do que se passa com os recém-nascidos, cujo comportamento tem um grande peso da maturação, como se a estrutura impusesse limites claros ao desempenho, nos idosos não se conhecem (ainda?) mecanismos senão maturativos, degenerativos, responsáveis pelo comportam ento" (Paúl, 1991: 42).
}

Com o conceito de envelhecimento activo acaba, a nosso ver, por se colocar a mesma exigência que veio a colocar com os conceitos de $3^{\text {a }}$ e 4⿳亠口冋 Idades: ou seja, a sua utilização crítica e não comprometida, por parte do discurso científico, dado que esses conceitos são sempre sedutoramente suscitadores de visões uniformes e redutoras. O que neste ponto do texto, referente ao processo de envelhecimento individual, queremos acentuar é que o próprio envelhecimento do sujeito é uma função parcialmente explicada pela sua história de vida, pela história social do seu grupo, e pelo meio em que se integra. Pelo que a promoção do envelhecimento activo é algo que respeita às políticas de saúde pública, de solidariedade social, mas igualmente às de transporte, habitação, promoção do espaço público, segurança pública, etc.

No entendimento de que envelhecimento activo corresponde a uma pré-noção científica, e que releva de visões uniformizadas sobre as condições sociais e individuais do processo de envelhecimento (produto social), ou seja, como sinónimo da velhice sã da sociedade contemporânea Ocidental, a sua utilização acrítica corresponde à negação do próprio objecto sociológico no campo da análise do envelhecimento humano e demográfico.

\section{Uma velhice em crise ou a crise} do modelo intergeracional

Referimo-nos, mais atrás, à crise do paradigma social, político e cultural do contrato social moderno. Essa crise está, de resto, longe de poder considerar-se debelada. Não nos referimos apenas ao desafio que o envelhecimento da população coloca hoje e nas próximas décadas à Segurança Social, desafios de sustentabilidade financeira do sistema mas também a sua sustentabilidade económica e social, como factor estruturante para o desenvolvimento económico e para a coesão social. De notar que esta crise foi alavancada pela mudança demográfica, mas as suas raízes encontram-se também profundamente no modelo macroeconómico e no enquadramento do mercado de trabalho, elementos estruturantes da vida colectiva e que se encontram esgotados. E é justamente a discussão deste esgotamento que cabe referir ao analisar o conceito de envelhecimento activo.

Sem prejuízo de se considerar a alavancagem do factor demográfico, a verdade é que a transformação sensível da vida social não se tem processado sem gerar contradições, tensões e efeitos indesejados (não esperados); dir-se-ia, uma certa instabilidade normativa e valorativa que afectou o valor social das pessoas de mais idade, sobretudo no mercado de trabalho e no âmbito mais vasto das relações sociais de produção. Tais transformações determinaram uma substituição geracional abrupta no mercado de trabalho, ao mesmo tempo a que se assistia a um prolongamento significativo da longevidade média da população Ocidental. Medidas houve, em Portugal e na generalidade dos países Ocidentais, que apoiaram e incentivaram até a saída precoce da chamada vida activa, associadas ao saneamento financeiro das empresas, mas não só, numa lógica geracionalmente pouco solidária.

A lógica do momento e do compromisso político sincrónico fez esquecer a espessura temporal dilatada dos processos de relação intergeracional e o efeito de longo prazo das medidas de saneamento. O hiato temporal gerado pela desparticipação da esfera laboral e o calendário da morte criou em muitos grupos sócio-profissionais, sobretudo dos sectores secundário e terciário, o vazio ocupacional. A ideologia da $3^{\text {a }}$ Idade procurou funcionar como um paliativo para esse hiato, mas o (in)sucesso dessa ideologia pode medir-se pelo facto de não ter conseguido transformar os idosos aposentados/ / reformados numa geração efectiva, no sentido em que para reconhecer a existência de uma geração efectiva é indispensável que se identifique uma unidade de consciência comportamental que tenha sido moldada por experiências partilhadas através de posições similares na estrutura social. Tal fenómeno nunca ocorreu nos últimos 50 anos. 
Em rigor, e importa perceber este facto histórico, a sucessão geracional - ou metabolismo demográfico como a designou Ryder (1997) - precedente à nossa contemporaneidade sempre se baseou numa lógica mais individual, em que a condição própria de cada indivíduo era determinante no processo de sucessão e as relações sociais do tipo particularista se sobrepunham às relações sociais do tipo universalista. A normalização etária e o processo substitutivo contemporâneo, encarado sob vários pontos de vista, e adequadamente, como uma aquisição civilizacional relevante, não deixou, porém, de gerar efeitos nefastos, que parcialmente as políticas do envelhecimento activo querem agora contrariar. Dir-se-ia que estamos diante de uma nova agenda de políticas para um problema social que se viu agravado nas últimas décadas.

Há que perceber que a sucessão geracional sempre foi, ao longo da história da humanidade, um princípio central na organização das sociedades, na medida em que as sociedades organizam a distribuição de prémios e oportunidades, e desenvolvem expectativas de comportamentos baseadas em diferentes características estratificadoras dos seus elementos, sendo a idade um elemento central nesses sistemas de estratificação. Todavia, nas sociedades do Estado de Bem-Estar, esse nexo entre gerações, como o designa Ribeiro Mendes (2005) está hoje gravemente comprometido, e a competitividade intergeracional muito degradada. Ou seja, a factura do índice de dependência real (a factura com as prestações sociais dos mais velhos) é maior do que a factura no investimento das gerações mais novas, deixando a estas um futuro sombrio. Esta circunstância, só parcialmente explicada pela demografia, é uma consequência directa do que Ribeiro Mendes apelidou de conspiração grisalha, e que se explica por ter sido a geração sanduíche a tratar dos seus interesses (como futuros idosos), transferindo os custos para os promitentes activos. A clivagem geracional é assim sistematizada:

\footnotetext{
"É que boa parte das posições economicamente activas e muitos dos postos de comando do Estado, das empresas e das instituições da sociedade civil estavam nas mãos de pessoas pertencentes às gerações entradas na vida adulta e no mercado de trabalho no final dos anos 60 e início dos anos 70" (Mendes, 2005: 134).
}

Entre nós - e repare-se na proximidade das datas dos três primeiros diplomas que a seguir se enunciam - só com a nova reforma da Lei de Bases da Segurança Social (Lei n. ${ }^{4 / 2007}$, de 16 de Janeiro), que revogou a que se encontrava em vigor desde 2002 (Lei n. ${ }^{\circ}$ 32/2002, de 20 de Dezembro), e que

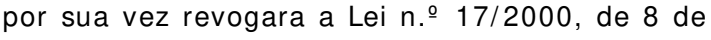

Agosto, que tinha vindo substituir a Lei n. $028 / 84$, de 14 de Agosto, se consagrou o factor de sustentabilidade das pensões - definido pela relação entre a esperança média de vida verificada num determinado ano de referência e a esperança média de vida que se verificar no ano anterior ao do requerimento da pensão. O que pode parecer um detalhe técnico para penalizar a antecipação da reforma, revela-se na nossa perspectiva como um elemento fundamental para a compreensão do significado atribuído pelo legislador à relação intergeracional e, porque não admitir, à própria relevância atribuída ao trabalho como parte integrante da vida dos trabalhadores com mais idade.

Entre o que se pode considerar a primeira formalização de um sistema nacional (quase) integral de gestão dos riscos sociais, plasmado na Lei $n .0$ 28/84, de 14 de Agosto - ainda na linha do incipiente modelo de 1962 (Lei $n=2115$, de 18 de Junho) -, e a revisão de 2007 (Lei n. 4/2007), muito mudou. Demograficamente, dir-se-á que as tendências que se perspectivavam no início dos anos 80 viram-se confirmadas e até reforçadas. Externamente, a influência do chamado Modelo Social Europeu ganhou uma importância incontornável. Politicamente, os Governos nacionais - depois de uma tentativa frustrada de proceder a reformas indolores, viram-se forçados a um reformismo pragmático em nome da sustentabilidade futura do sistema de Segurança Social que integra agora os princípios da diferenciação positiva ("flexibilização e modulação das prestações em função dos rendimentos, das eventualidades sociais e de outros factores, nomeadamente, de natureza familiar, social, laboral e demográfica", cfr.

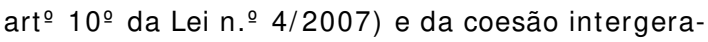
cional ("ajustado equilíbrio e equidade geracionais na assunção das responsabilidades do sistema", cfr. artำ $13^{\circ}$, idem) de modo substantivamente diferente do que acontecera na reforma de 2000 , e até de modo inédito (se a comparação se fizer com o texto da Lei de Bases de 1984). Socialmente, a transformação das condições da reforma, nomeadamente do calendário em que ocorre, adiando o momento, penalizando a antecipação, foi talvez a principal de todas as contestações e reforçou na discussão pública a questão da (falsa) descontinuidade entre o período activo e o "éden" (entendido como sinónimo de desvinculação da responsabilidade do trabalho). Sendo mais evidente junto de largos sectores socioprofissionais da Administração Pública, a verdade é que o sector empresarial privado ou participado pelo Estado - com excepção mais evidente para as empresas que se encontram em processos de saneamento financeiro percebeu que essa descontinuidade abrupta se torna funcional e organizacionalmente insustentável, pelo que começa a ser prática corrente que a reforma do trabalhador, sobretudo dos mais qualificados, dê lugar à sua posterior (re)contratação como aven- 
çado, consultor, colaborador eventual, fazendo do reformado e precocemente idoso, um envelhecido activo. As soluções de trabalho voluntário não se inscrevem nesta lógica.

De acordo com os dados disponíveis pelo Inquérito do Emprego (ver Gráfico 3), e procurando captar o que se modificou na última década em termos do emprego das pessoas com mais de 65 anos, apenas $6,1 \%$ dos activos masculinos e $5,6 \%$ dos activos femininos têm essa idade. Dez anos antes esses valores eram praticamente idênticos (respectivamente $5,5 \%$ e $5,1 \%$ ).

Porém, quando analisamos a distribuição da população activa por nível de escolaridade, verificamos um efeito de geração muito vincado, dado que os idosos activos não têm ganho posição percentual junto da população mais qualificada, e pelo contrário estão remetidos para um nicho de activos pouco ou nada qualificados. Em 1998 representavam $27 \%$ dos activos masculinos sem habilitações, e
Já havíamos identificado esta iniquidade diante do mercado de trabalho em análises anteriores (Machado, 2007), recorrendo então aos dados dos grupos socio-económicos dos Censos de 2001. Repare-se que em todos os grupos socio-económicos representados no Gráfico 4 (e que são os aqueles em que a representatividade de trabalhadores com idades compreendidas entre os 55 e os 64 anos era mais elevada), a variação é muito acentuada, ainda que diferenciada. Na transição dos 65 anos, assiste-se a um desaparecimento massivo de pessoas activas. Mesmo que algumas delas, obtida a reforma por velhice, continuem a trabalhar - o que poderá verificar-se mais facilmente entre os trabalhadores independentes, patrões e empresários - o facto é que permanece a dúvida sobre a capacidade de uma sociedade (e a sua economia), com forte depauperamento de recursos qualificados, pode manter esta fractura geracional por muito mais tempo.

Gráfico $3 \triangleright$ Evolução da proporção da população activa idosa no conjunto da população activa (Série 1998), por sexo e nível de escolaridade mais elevado completo

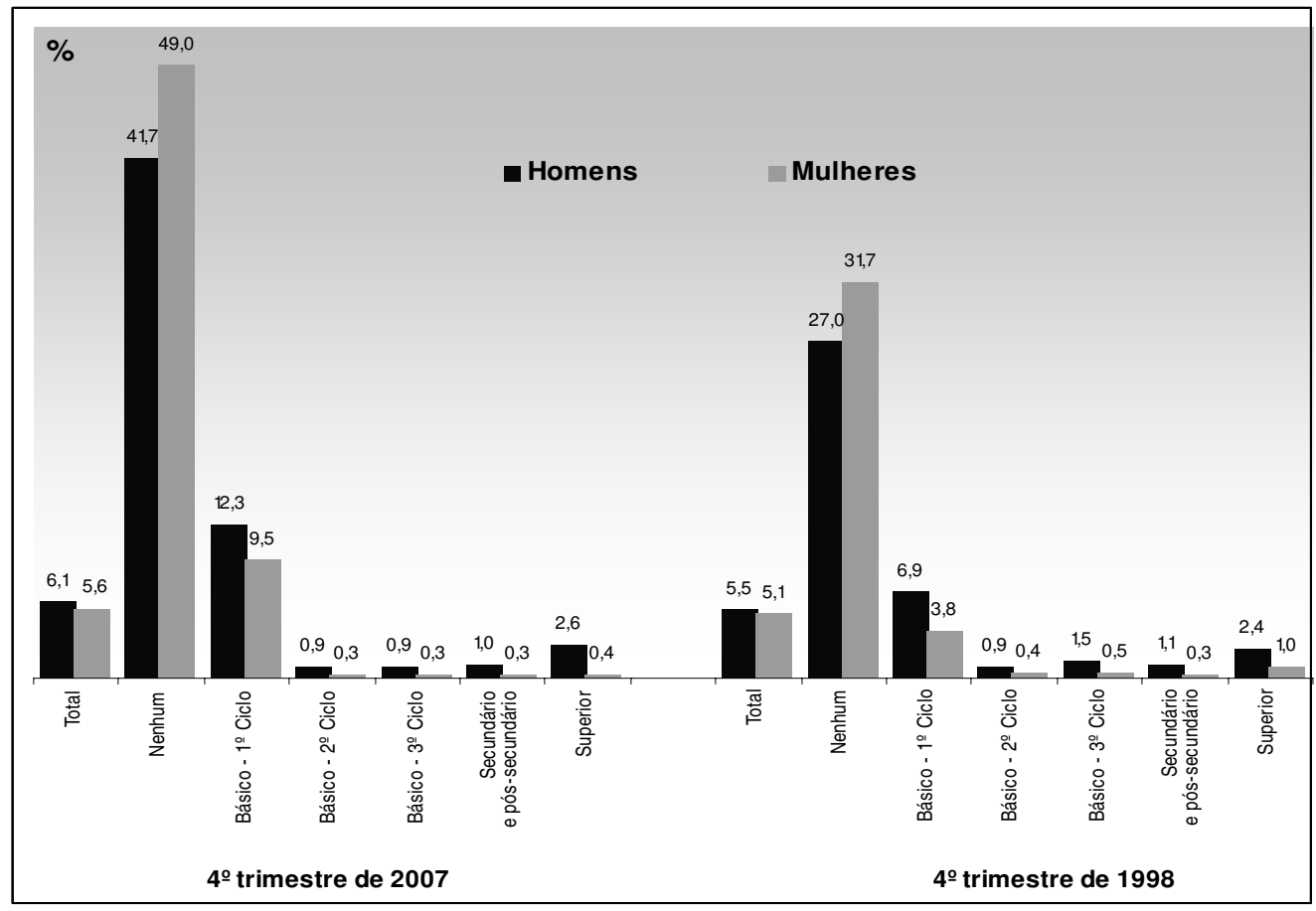

Fonte: INE, Inquérito ao Emprego. Cálculos efectuados por nós.

dez anos volvidos já representam $41,7 \%$. No que respeita às mulheres idosas, passaram a representar quase metade (49\%) das activas sem qualificações, mas há dez anos representavam já 31,7\%. Com o nível de escolaridade mínimo (básico - 1ำciclo), a tendência tem sido idêntica.
Aparentemente, o factor de sustentabilidade pretende travar a saída precoce e estimular o prolongamento da vida activa por mais algum tempo, mas não evitará que se procurem novas medidas destinadas a estimular o crescimento da produtividade e que se entendem como incontornáveis para 
Gráfico $4 \triangleright$ Variação da proporção de activos por grupo sócio-económico, através do método da comparação directa entre coortes

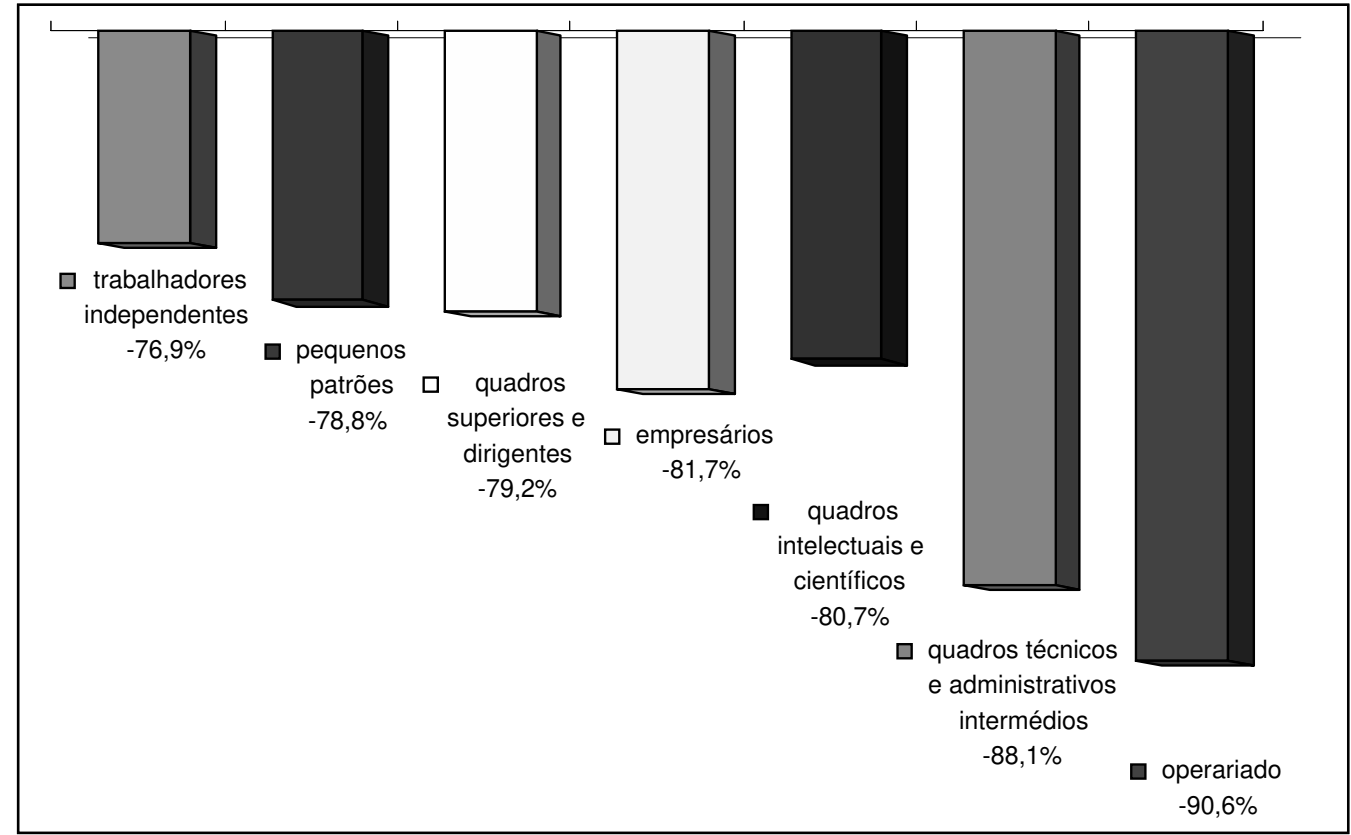

Fonte: INE, Censos 2001. Cálculos efectuados por nós 5 .

superar as consequências do envelhecimento sobre o crescimento económico. O corte formal com a vida profissional aos 65 anos é brutal - e a deriva para o sector informal não se proporciona a todos nem garante uma posterior segurança financeira -, pouco consentâneo com os reequilíbrios financeiros do sistema de segurança social, geracionalmente injusto e individualmente penalizador, sendo relevante, de um ponto de vista sociológico, perceber o significado concreto da actividade dos sujeitos no período do seu envelhecimento individual e no contexto em que uma e outro ocorrem. Do Plano Nacional de Emprego 2005-2008 consta, como meta Europeia para 2010 aumentar em mais 5 anos a idade média efectiva de saída do mercado de trabalho (que em 2005 se situaria, de acordo com o Eurostat, em 63,1 anos).

Do político ao social, ou de como a realidade social é sempre mais complexa do que a proposição reformista

Portugal, à semelhança do que vem acontecendo com outros países Ocidentais, tem vindo a integrar os objectivos da política de envelhecimento activo nos diferentes instrumentos de política social. No nosso caso, com destaque para o Plano Nacional de Saúde (PNS) e para o Plano Nacional de Emprego (PNE). Em relação ao PNS foi definido um instrumento operacional denominado Programa Nacional para a Saúde das Pessoas Idosas (2004). No âm bito do PNE 2005-2008, e integrado no desafio da modernização do sistema de protecção social (Desafio 5), o Governo entendeu, em resposta a uma recomendação formulada em 2004 pelo Conselho Europeu, desencadear os trabalhos, em sede da Concertação Social, conducentes à formulação de uma Estratégia Nacional de Envelhecimento Activo (ENEA). Pretende o reformador que a ENEA seja um Plano de Acção assente numa abordagem global e coerente, actuando em vários domínios e para fomentar, numa óptica sobretudo preventiva, a participação económica sustentada dos indivíduos ao longo de todo o seu percurso de vida. Numa óptica reparadora, a ENEA pretende combater não só o desem prego dos trabalhadores mais velhos (que se vêm considerando como aqueles com mais de 50 anos!), como também a passagem hoje em regra generalizada à inactividade, incentivando o retorno dos mesmos ao mercado de trabalho.

Para além das questões que os parceiros (das confederações sindicais e patronais) colocam, com perspectivas diferentes e porventura antagónicas, às ópticas preventiva e reparadora, o próprio actor político proponente identifica um conjunto relevante de questões críticas para a eficácia da estratégia, a saber: 
i) "a tendência para a saída precoce do mercado de trabalho (nomeadamente por via de reformas antecipadas);

ii) a escassez de ofertas de emprego disponíveis;

iii) o reduzido número de instrumentos de política activa disponíveis para este segmento;

iv) a maior incidência de baixas qualificações;

v) o menor acesso a informação e/ou disponibilidade para a activação por parte destes públicos" (MTSS, 2007)

Se em relação ao Plano Nacional de Saúde, a ênfase sobre o envelhecimento activo se orienta no sentido da obtenção de ganhos em anos de vida com independência (i.e., viver com independência na com unidade sem ajuda ou com pequena ajuda de outrem), o que pressupõe a adequação dos cuidados às necessidades das pessoas idosas e a promoção do desenvolvimento de ambientes capacitadores, no Plano Nacional de Emprego, e mais concretamente na Estratégia Nacional de Envelhecimento Activo, a ênfase recai sobre a criação de condições para atribuir um significado e um sentido aos ganhos alcançados em termos de duração de vida. Essas condições, em nosso entender, só podem ser entendidas quando pensamos as questões do envelhecimento à escala local. As respostas aos problemas suscitados pela (própria) agenda do envelhecimento activo deixam de ser do domínio restrito das políticas sociais para se insinuarem nas políticas do território.

\section{Do societal ao local: como promover o envelhecimento activo integrado no desenvolvimento urbano}

É neste contexto de fortes transformações sociais, nom eadam ente da evolução das relações de tipo particularista para as relações de tipo universalista, dos desequilíbrios numéricos e afastamentos (físicos) entre estratos etários, do perfil e desempenho das economias nacionais (e da economia global), do aparecimento do Estado mediador e providente, das dificuldades que encontra na satisfação dos seus compromissos, que se pode colocar a questão sociológica do envelhecimento das sociedades.

No que respeita às cidades, as tradicionais dimensões da análise social do envelhecimento e da velhice (rendimento, saúde/bem-estar, educação, lazer, sociabilidades e políticas sociais), que permitem identificar uma condição social da velhice em perda, revelam-se já insuficientes. Novas dimensões analíticas ganham actualidade e sugerem novas temáticas e possíveis feixes problematizadores: condições habitacionais (desfavoráveis); segregação residencial (crescente); adequação (funcional) dos cenários comportamentais destes urbanitas (por nascimento ou adopção) mais idosos; utilização do espaço público (em que as questões da segurança se colocam com particular acuidade); respostas institucionais à dependência (sobretudo dos muito idosos); violação dos direitos humanos (com destaque para a violência doméstica exercida por familiares), são exemplos do alargamento possível de um modelo de análise para captar a mudança dos quadros sociais em meio urbano. Mas são também, na nossa perspectiva, os feixes das políticas que visem promover o envelhecimento activo dos cidadãos.

A questão sócio-política está identificada: como envelhecer em meio urbano, garantindo a coesão social e a cidadania de todos? Pelas nossas palavras, como superar a discrepância significativa entre padrões sociais e a realidade social? Uma sociologia do envelhecimento e da velhice em meio urbano, numa perspectiva ecológica, como aquela que defendemos (Machado, 2007) impõe uma matriz de compreensão sobre as mudanças que ocorrem na estrutura demográfica urbana (campo da morfologia social), no habitat urbano (campo das complexidades ecossistémicas e de confrontação ideológica, simbólica e política), e nos quadros e processos de acção que moldam as relações geracionais e intergrupais (campo da análise accionista).

A agenda do envelhecimento activo, como ficou recentemente reflectido na Declaração de Leon (Espanha), cujo objectivo consiste em suportar a implementação do Plano de Acção sobre o Envelhecimento, aprovado em Madrid, em Abril de 2002, pressupõe medidas de nível estratégico e de nível operacional. Entre estas últimas, é recomendada a criação de um Instituto Europeu sobre o Envelhecimento que promova, entre outros temas de investigação considerada prioritária, os temas da prevenção a longo prazo e promoção da saúde física, psicológica, espiritual e social (sem as quais, diríamos nós, não se pode falar em envelhecimento activo), e do próprio envelhecimento activo: mobilidade e ambiente, qualidade de vida e estilos de vida saudáveis.

Não parece provável que a insistência em modelos de organização colectiva assentes num cada vez menor nexo geracional, e sem cuidar de conhecer e compreender a interacção e o mútuo condicionamento entre os quadros e os processos de acção social, as políticas e normas técnicas e as comunidades humanas, e os reflexos destas interacções na mudança social, ao nível do habitat urbano, contribuindo para a capacidade destas formularem políticas adequadas ao seu devir, não parece provável que essa insistência, dizíamos, seja uma via procedimental adequada quando se pensa o envelhecimento e a velhice em meio urbano. 


\section{Notas}

Definido habitualmente como o quociente entre o número de pessoas com 75 ou mais anos e o número de pessoas com 65 ou mais anos (expressa em \%)). A fórmula de cálculo é a seguinte: $\mathrm{IL}=[(\mathrm{P}(75,+) /$ / $\mathrm{P}(65,+)]^{\star} 100$.

2 A longevidade biológica (marcada por outros compassos menos sociais) mantém-se relativamente inalterada. Regista-se, frequentemente, uma confusão entre o alongamento do tempo de vida de uma coorte com o aumento da longevidade dos indivíduos, porventura devido à utilização (abusiva) do termo anglo-saxónico longevity como sinónimo do valor da probabilidade de sobrevivência à idade $x$. A este propósito convém reter a explicação de Pressat (1985): "Although average life expectancy has increased greatly since pre-industrial times the maximum lenght of time seems to be little altered and to be somewaht over 100 years. Reports of special populations with high proportions of centenarians have all proved to be based on poor data with considerable age over-statement".

3 Lembramos que Max Weber havia chamado a atenção para esta ausência de sentido que as sociedades contemporâneas atribuem à morte, na sua célebre conferência sobre a Ciência como Profissão, proferida em Janeiro de 1919. A questão central colocada consistiu na relação que se poderia estabelecer entre a ciência e os valores que actuam como orientadores da vida humana. Baseando-se na noção de processo histórico de racionalização ocorrido no Ocidente, que teria permitido o desenvolvimento de diferentes maneiras de entender a vida e o Mundo, bem como de distintos sistemas de valores, tributários da racionalização e contrários à explicação sacralizada, a morte, segundo Max Weber, aparece como um acontecimento contrário (porque irreversível) ao sentido de progresso do conhecimento científico (que não se interrompe).

4 Em reforço deste grupo de teorias, também conhecidas por físico-químicas, avanços científicos recentes (publicados na revista Nature, 2004) dão conta de que a chave do envelhecimento está no ADN mitocondrial, resultante de uma série de pequenas alterações de um componente genético celular chamado ADN mitocondrial. Essas mutações podem causar várias alterações associadas ao envelhecimento, embora nem todo o envelhecimento tenha origem nessas mutações. A mitocôndria é como uma central bioquímica que existe nas células com a função de conversor energético, contendo porções de ADN próprio que estão separadas do núcleo da célula, onde residem os genes do corpo. Estes resultados são, ainda, consistentes com a teoria de que os chamados "radicais livres" desempenham um papel no envelhecimento.

5 As coortes comparadas foram: população activa com idades compreendidas entre os 55 e os 64 anos vs. população activa com idades compreendidas entre os 65 e os 74 anos

\section{Referências bibliográficas}

ARIÈS, P. (1977), O Homem Perante a Morte, Mem- Martins, Publicações Europa-América.

INE (2000), Esperança de Vida sem Incapacidade Física de Longa Duração, Caderno Temático, 10, Lisboa, INE.

INSA (2001), Inquérito Nacional de Saúde 1998/1999. Continente. Dados Gerais, Lisboa, Instituto Nacional de Saúde.

MACHADO, P. (2007), As malhas que a (c)idade tece. Mudança social, envelhecimento e velhice em meio urbano, TPI 44, Lisboa, LNEC.

MARTINS, H. (1985), "Tristes Durées", R. Feijó, H. Martins e J.P. Cabral [orgs], A Morte no Portugal Contemporâneo - Aproximações Sociológicas, Literárias e Históricas, Lisboa, Querco.

MENDES, F. R. (2005), Conspiração Grisalha: Segurança Social, Competitividade e Gerações, Oeiras, Celta.

MTSS (2006), Linhas Estratégicas da Reforma da Segurança Social, Lisboa, MTSS.

MTSS (2007), Plano Nacional de Emprego (2005 -2008) - Relatório de Acompanhamento 2006, Gabinete de Estratégia e Planeamento, Lisboa, MTSS.

OMS (2002), Relatório Mundial da Saúde 2001. Saúde mental: nova concepção, nova esperança, Lisboa, Direcção-Geral da Saúde/OMS.

PAÚl, C. (1991), Percursos pela Velhice - uma perspectiva ecológica em psicogerontologia, Porto, Instituto de Ciências Biomédicas de Abel Salazar - Universidade do Porto (tese policopiada).

PRESSAT, R. (1985), The Dictionary of Demography, Oxford, Blackwell.

RILEY, M., A. Foner e J. Waring (1988), "Sociology of Age" in N. Smelser (ed.) Handbook of Sociology, London, Sage.

RYDER, N. (1997; 1a edição de 1965), "The Cohort as a Concept in the Study of Social Change", M. Hardy [ed.] (1997), Studying Aging and Social Change - conceptual and methodological issues, London, Sage, pp. 66-92.

TOURAINE, A. (1982), Pela Sociologia, Lisboa, D. Quixote.

WHO (2002), Active Ageing - A Policy Framework, Geneva, WHO.

SANTOS, B. SOUSA (1998), Reinventar a Democracia, Cadernos Democráticos, nำ 4, Lisboa, Fundação Mário Soares/Gradiva. 